\title{
EFFECT OF ACTIVE CONFINEMENT ON SHEAR BEHAVIORS FOR PILE CAP PRESTRESSED LATERALLY
}

\author{
K. YAMASHITA ${ }^{*}$, R. YAMASHITA ${ }^{\dagger}$ Y.SHINOHARA ${ }^{\dagger \dagger}$ \\ *Tokyo Institute of Technology \\ Yokohama, Japan \\ e-mail: yamashita.k.ao@m.titech.ac.jp \\ ${ }^{\dagger}$ Emachu Holdings Co., Ltd. \\ Tokyo, Japan \\ e-mail: ryo.yamashita@emachu.co.jp \\ ${ }^{\dagger \dagger}$ Tokyo Institute of Technology \\ Yokohama, Japan \\ e-mail: shinohara.y.ab@m.titech.ac.jp
}

Key words: Pile cap, Precast pile, Coefficient of friction, Interface, Lateral prestress

\begin{abstract}
The recent design requirement for a pile foundation often causes the pile head joint (hereafter, pile cap) to overcrowd the arrangement of reinforcements and to expand the dimensions. In order to solve this problem without increasing in dimension of the pile cap, the introduction of lateral prestress to the pile cap may be effective in improving the shear capacity. In the present study, the validity of analytical models is verified first by comparing the results through 3D FEM approaches against the test results performed on a partial pile foundation previously. After that, the improvement of earthquake resistance and durability by introducing lateral prestress to pile caps are investigated based on the triaxial state of stress. The analysis results indicated that the lateral prestress controls the shear crack effectively and increases the shear capacity of the pile cap by over 30 percent. However, some vertical tension reinforcements yielded in this analysis, therefore the introduction of vertical prestress in addition to lateral prestress to the pile cap may prevent yielding of vertical reinforcements and further improve the shear capacity.
\end{abstract}

\section{INTRODUCTION}

Recently, the shear and flexural capacities of piles have drastically improved and the ultimate design is also required for the pile foundations of medium and high-rise buildings, as well as for the superstructures. As a result, the pile cap to be sufficient for the required ultimate strength increases in dimensions or causes the overcrowding arrangement of reinforcements. In the previous studies, the experiment of a partial pile foundation was conducted to investigate the shear fracture behavior of pile cap [Kokusho et al. 1983]. According to this experiment, the maximum shear capacity was determined by the widening of the cracks developing in the diagonal direction of the pile cap which is corresponding to the direction of a compression strut generated in the pile cap. In order to control this crack widening, the introduction of lateral prestress to the pile cap may be effective because the shear crack strength and shear capacity of the reinforced concrete (hereafter, RC) column was greatly 
improved by introducing the lateral prestress [Shinohara et al. 2004]. In this study, the effect of confinement increased by the introduction of lateral prestress on the shear behaviours of the pile cap is evaluated using the equivalent confining pressure and the degree of damage. The objectives of the present study are (1) to verify the validity of analytical models in analysing the specimens of pile caps mentioned above, and (2) to investigate how the lateral prestress introduced to the pile cap improves the shear crack strength, the crack opening and the shear capacity based on the triaxial state of stress.

\section{OVER VIEW OF TEST}

\subsection{Test specimens and analysis models}

Figure 1 shows dimensions and cross sections of standard test specimen (RECB). Table 1 summarizes the specifications of this analysis specimens as well as the previous test specimens. The analysis specimens contain a redoubled foundation. The test specimens are divided into two types, one has square transverse bars in the pile cap (RECB) and the other circular transverse bars (CIRB). The shear span ratio is 3.0 based on the moment distribution in underground piles. The diameter and the embeded depth of the pile are $300 \mathrm{~mm}$. D13 reinforcements are basically used but D22 reinforcements are installed for longitudinal bars of the foundation beam. A typical crack behavior observrd during the tests was that the cracks in the orthogonal direction of the loading direction initially appeared and opened. However, the maximum capacity was determined by the widening of the cracks developed in the diagonal direction corresponding to the direction of compression strut in the pile cap. The concrete compressive strength of the pile cap were $26.5 \mathrm{~N} / \mathrm{mm}^{2}$ and $25.4 \mathrm{~N} / \mathrm{mm}^{2}$ for RECB and CIRB respectively. RECB and CIRB were prepared in order to study the reinforcing effect due to the different configurations of the transverse bars. Therefore, the similar volume ratios of reinforcement to concrete are used for RECB (1.4\%) and CIRB $(1.5 \%)$. The pile caps had a square, and the side is $720 \mathrm{~mm}$ which is 2.4 times of the pile diameter. The foundation beam was $500 \mathrm{~mm}$ in width, and $600 \mathrm{~mm}$ in height. The steel cap for loading was attached at the top of the pile. Table 2 shows the mechanical properties of the concrete and reinforcements.

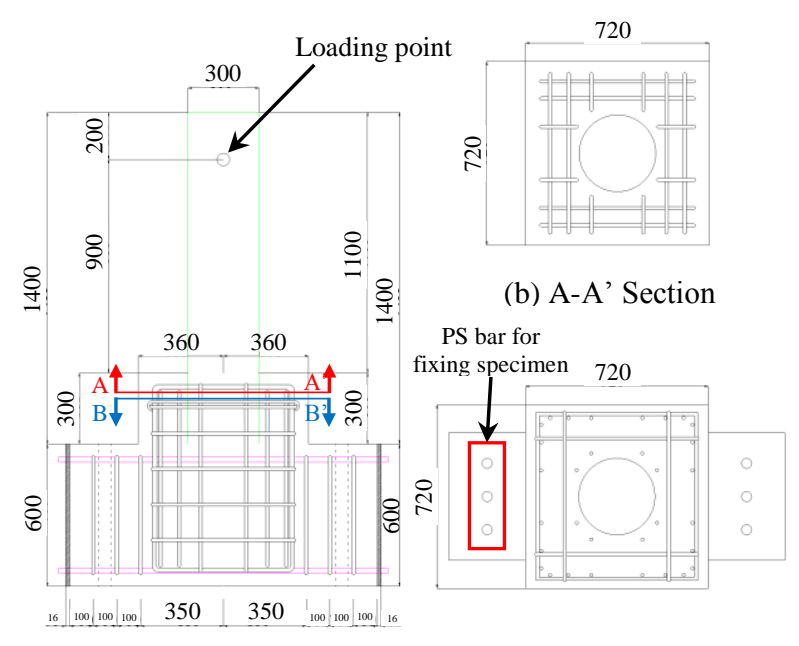

(a) Elevation

(c) B-B' Section

(Unit: $\mathrm{mm}$ )

Table 1: List of analysis object

\begin{tabular}{|c|c|c|c|c|c|c|}
\hline Designation & $\begin{array}{l}\text { Prestressing } \\
\text { Ratio } \sigma_{p} / \sigma_{B}\end{array}$ & $\begin{array}{l}\text { Shape of } \\
\text { trans. bars }\end{array}$ & $\begin{array}{l}\text { Pile diameter } \\
(\mathrm{mm})\end{array}$ & $\begin{array}{l}\text { Embeded } \\
\text { depth } \\
(\mathrm{mm})\end{array}$ & $\begin{array}{l}\text { Size of pile cap } \\
(L \times W \times H) \\
(\mathrm{mm})\end{array}$ & Remarks \\
\hline RECB & 0 & Square & \multirow{2}{*}{300} & \multirow{2}{*}{300} & \multirow{2}{*}{$720 \times 720 \times 300$} & \multirow{2}{*}{$\begin{array}{l}\text { Tested and } \\
\text { analyzed }\end{array}$} \\
\hline CIRB & 0 & Circle & & & & \\
\hline "P1-RECB & 0.025 & \multirow{3}{*}{ Square } & \multirow{3}{*}{300} & \multirow{3}{*}{300} & \multirow{3}{*}{$720 \times 720 \times 300$} & \multirow{3}{*}{$\begin{array}{l}\text { Analyzed by } \\
\text { prestressing }\end{array}$} \\
\hline P3-RECB & 0.075 & & & & & \\
\hline P6-RECB & 0.150 & & & & & \\
\hline L-RECB & 0 & \multirow{2}{*}{ Square } & \multirow{2}{*}{600} & \multirow{2}{*}{600} & \multirow{2}{*}{$1440 \times 1440 \times 600$} & \multirow{2}{*}{$\begin{array}{l}\text { Analyzed by } \\
\text { redobled size }\end{array}$} \\
\hline L-P6-RECB & 0.150 & & & & & \\
\hline
\end{tabular}

$\sigma_{B}=$ compressive strength of concrete

$\sigma_{p}=$ lateral pressure $(=P /(W \times H)$ where $\mathrm{P}$ is the amount of prestressing force $)$ 
Table 2: Mecanical properies for concrete and reinforcemnets

\begin{tabular}{|c|c|c|c|}
\hline $\begin{array}{c}\text { Concrete } \\
\text { (Pile cap) }\end{array}$ & $\begin{array}{c}\sigma_{B} \\
\left(\mathrm{~N} / \mathrm{mm}^{2}\right)\end{array}$ & $\begin{array}{c}\sigma_{c t} \\
\left(\mathrm{~N} / \mathrm{mm}^{2}\right)\end{array}$ & $\begin{array}{c}E_{c} \\
\left(\times 10^{4} \mathrm{~N} / \mathrm{mm}^{2}\right)\end{array}$ \\
\hline RECB & 26.5 & 2.08 & 2.38 \\
\hline CIRB & 25.4 & 1.94 & 2.35 \\
\hline $\begin{array}{c}\text { Concrete } \\
\text { (Pile) }\end{array}$ & 76.9 & 5.28 & 3.49 \\
\hline Reinforcement & $\begin{array}{c}\sigma_{y} \\
\left(\mathrm{~N} / \mathrm{mm}^{2}\right)\end{array}$ & $\begin{array}{c}\sigma_{s t} \\
\left(\mathrm{~N} / \mathrm{mm}^{2}\right)\end{array}$ & $\begin{array}{c}E_{s} \\
\left(\times 10^{5} \mathrm{~N} / \mathrm{mm}^{2}\right)\end{array}$ \\
\hline D13(SD295) & 354 & 511 & 1.81 \\
\hline
\end{tabular}

$\sigma_{B}=$ compressive strength of concrete

$\sigma_{c t}=$ splitting tensile strength of concrete

$E_{c}=$ young's modulus of concrete

$\sigma_{y}=$ yield strength

$\sigma_{s t}=$ tensile strength

$E_{s}=$ young's modulus of reinforcement

\subsection{Loading and measuring methods}

The specimen was installed in the loading apparatus upside down. The rotation angle, $R$ was found by dividing the horizontal displacement of the loading point by the height of the pile $(900 \mathrm{~mm})$. The axial force $(357 \mathrm{kN})$ was supplied initially, and the axial load ratio was consistently maintained at 0.12 during the test. After that the cyclic horizontal force was supplied with load control and reduced when it reached $\pm 53 \mathrm{kN}$ and $\pm 106 \mathrm{kN}$. Subsequently, it was switched to displacement control, and it was reduced when the rotation angle reached $\pm 1 / 200, \pm 1 / 150, \pm 1 / 100$, and $\pm 1 / 50$.

\section{OVER VIEW OF ANALYSIS}

\subsection{Over view of analytical model}

RECB and CIRB were analyzed using 3D $\mathrm{FE}$ analysis in order to verify the validity of analytical models. Furthermore, the lateral prestress is introduced to the pile cap at three different levels, to investigate the effect of confinement on the shear behaviors. Figure 2 shows the finite element mesh and boundary conditions. Concrete, steel plate, and steel cap were modeled by solid isoparametric elements. Regarding boundary conditions, the positions of prestressing bar (hereafter, PS bar) to anchor the specimen firmly to the frame, a journal jack and the base were supported by rollers. Due to the symmetry, only half of the specimen was modeled, and supported in the out of-plain direction. The friction interface was inserted between the embedded pile and concrete. The SC pile behaved elastically during the tests. For this reason, the pile (steel pipe and concrete) was modeled as an elastic body having the same flexural stiffness as the composite pile, as a result, the elastic modulus was assumed to be $75000 \mathrm{~N} / \mathrm{mm}^{2}$. A diameter of PS bar used in specimens was $32 \mathrm{~mm}$, and prestress force was horizontally introduced from two directions at the same time. The lateral prestress ratios, found by dividing prestressing force by prestressed gross section and concrete strength, are set to $0.025,0.075$, and 0.15 , and designated simply by P1-RECB, P3-RECB, and P6-RECB respectively. Unbonded PS bars were used in this analysis, and the position of PS bar was decided by a preliminary analysis which indicated the introduction of lateral prestress to the bottom side of the pile cap was the most effective in the increase of the shear capacity. Moreover, the steel pressure-resisting plate was also modeled to avoid a local failure caused by a direct introduction of prestress. Furthermore, L-RECB and L-P6-RECB having a double dimension of RECB and P6-RECB were analysed to study the scale effect. The number of PS bars of L-P6-RECB was 4 times of P6RECB so that, the PS bar of both models is exactly equivalent in the amount of prestressing force.

\subsection{Analytical model for concrete, reinforcement and interface}

Figure 3 shows analytical model for concrete and reinforcements. Popovics model was applied to the compressive rising zone of the concrete and after the peak stress, it was assumed to be a linear softening. DruckerPrager criterion was used as the compressive failure criterion, and the internal friction angle was estimated as $20^{\circ}$. A crack arises when the maximum principal stress exceeds the tensile strength, and it was assumed that the fracture energy was $0.1\left(\mathrm{~N} / \mathrm{mm}^{2}\right)$ with linear softening in the softening zone. The shear stiffness after cracking was reduced using a shear transfer 


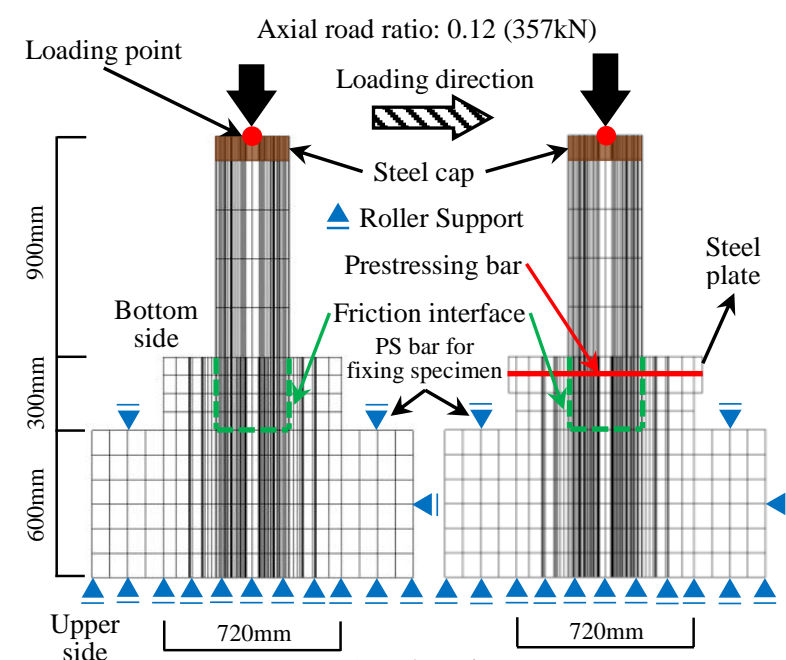

(a) Elevation

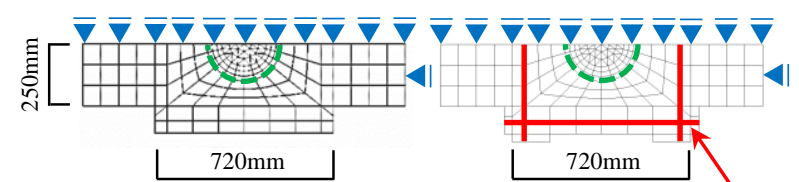

(b) Section

Figure 2: Finite element mesh

Prestressing bar

(Left: RECB, Right: P1-RECB)

coefficient $\beta$ expressed by the function of crack strain $\varepsilon_{c r}$. The interface element between the pile and footing was modeled as the friction model which doesn't transmit any tensile force, and the coefficient of friction was set to 0.4 according to AIJ design standard for steel structures. The second shear stiffness of the interface was assumed to be $3.0\left(\mathrm{~N} / \mathrm{mm}^{2} / \mathrm{mm}\right)$, as half of the second stiffness of Hayashi bondslip model (1982) The stress-strain relationship of reinforcement was expressed as bi-linear model, and the stiffness after yielding was onehundredth of initial stiffness. The complete bond between concrete and reinforcement was assumed.

\section{ANALYSIS RESULTS OF RECB AND CIRB SPECIMEN}

\subsection{Load $(Q)$-rotation angle $(R)$ relations}

Figure 4 shows load $(Q)$-rotation angle $(R)$ relations, and Table 3 shows the maximum capacity and the rotation angle at peak load. According to the analysis results of RECB and CIRB, the ultimate strength was determined by the widening of the cracks developed in the diagonal direction (B-B' direction in Figure 6)
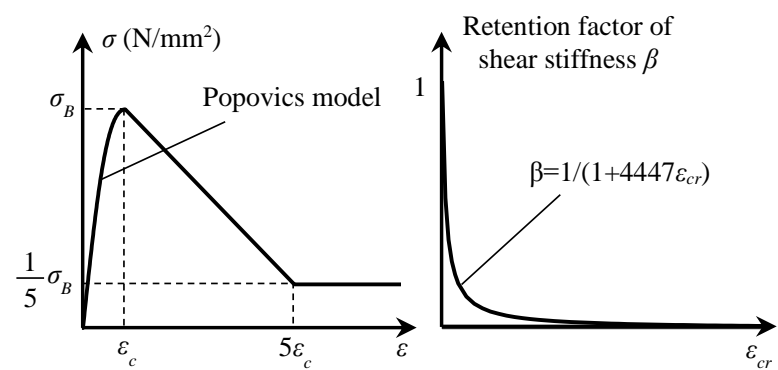

Compressive stress-strain curve

Deterioration ratio of shear stiffness

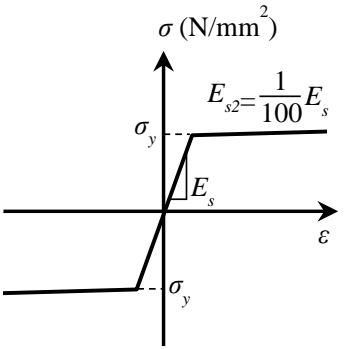

Stress-strain curve

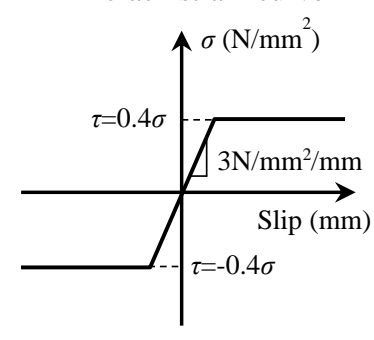

Friction model for shear direction
Figure 3: Analytical model for concrete and reinforcements

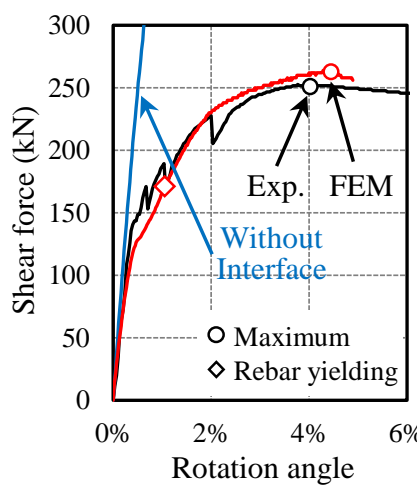

(a) RECB

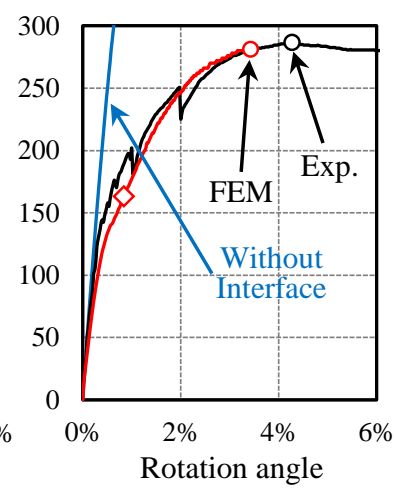

(b) CIRB
Figure 4: Load-rotation angle relations

Table 3: Maximum capacity in test and analysis

\begin{tabular}{|c|c|c|c|c|}
\hline $\begin{array}{c}\text { Test } \\
\text { Disignation }\end{array}$ & $\begin{array}{c}Q_{\text {exp }} \\
(\mathrm{kN})\end{array}$ & $\begin{array}{c}R_{\exp } \\
(\%)\end{array}$ & $\begin{array}{c}Q_{\text {FEM }} \\
(\mathrm{kN})\end{array}$ & $\begin{array}{c}R_{\text {FEM }} \\
(\%)\end{array}$ \\
\hline RECB & 253 & 3.77 & 264 & 4.44 \\
\hline CIRB & 286 & 4.16 & 282 & 3.42 \\
\hline
\end{tabular}

$Q_{\text {exp }}$ : maximum capaity by experiment

$R_{\text {exp }}$ : rotation angle at maximum capacity by experiment $Q_{F E M}$ : maximum capaity by FEM analysis

$R_{F E M}$ : rotation angle at maximum capacity by FEM analysis

corresponding to the direction of compression strut formed in the pile cap, which is consistent with the test results. The maximum capacity and stiffness were highly overestimated when 
analyzing without an interface between the pile and pile cap. However, the analysis results closely agree with the test results by inserting a friction interface between the pile and pile cap. This interface has a mechanical properties described in Sec. 3.2. The stiffness was somewhat underestimated compared to the test results until shear force reached nearly to $200 \mathrm{kN}$ because the cohesion between the pile and pile cap was not considered in the analyses. Regarding RECB, the first reinforcement yielding occurred in a vertical reinforcement at the loading direction side in vicinity of pile when $R=1.02 \%$ and $Q=168 \mathrm{kN}$. While regarding CIRB, the first reinforcement yielding occurred in a circular reinforcement (transverse bar) crossing a large crack in B-B' area. at $R=0.76 \%$ and $Q=155 \mathrm{kN}$, The maximum shear load of CIRB increases by more than $10 \%$ compared with that of RECB because of a better confinement of circular transverse bars.

\subsection{Strain of transverse reinforcements at $R=2 \%$}

Figure 5 shows the strain of transverse reinforcements of RECB and CIRB when $R=2 \%$. Analysis results show the values of gauss integration points near the strain gauges. The yield strain of reinforcement is $1960 \mu$. Reinforcements at bottom side in the loading direction yielded in this analysis, whereas they didn't yield in the experiments. However, analysis results indicate that the forward strain in loading was larger than the backward strain. This result corresponded to the test result. Furthermore, analysis results gave a tendency that the yielding transverse reinforcement is roughly consistent with the test results.

\subsection{Crack patterns at $R=2 \%$}

Figure 6 compares cracking strain contour from the analysis with crack patterns from the experiment when $R=2 \%$. In the experiments, cracks initially appeared in A-A' area in the both specimens, afterward cracks in B-B' area developed and finally dominated up to the maximum capacity. The maximum capacity of the analysis was also determined by the cracks in B-B' area, therefore the analysis results are

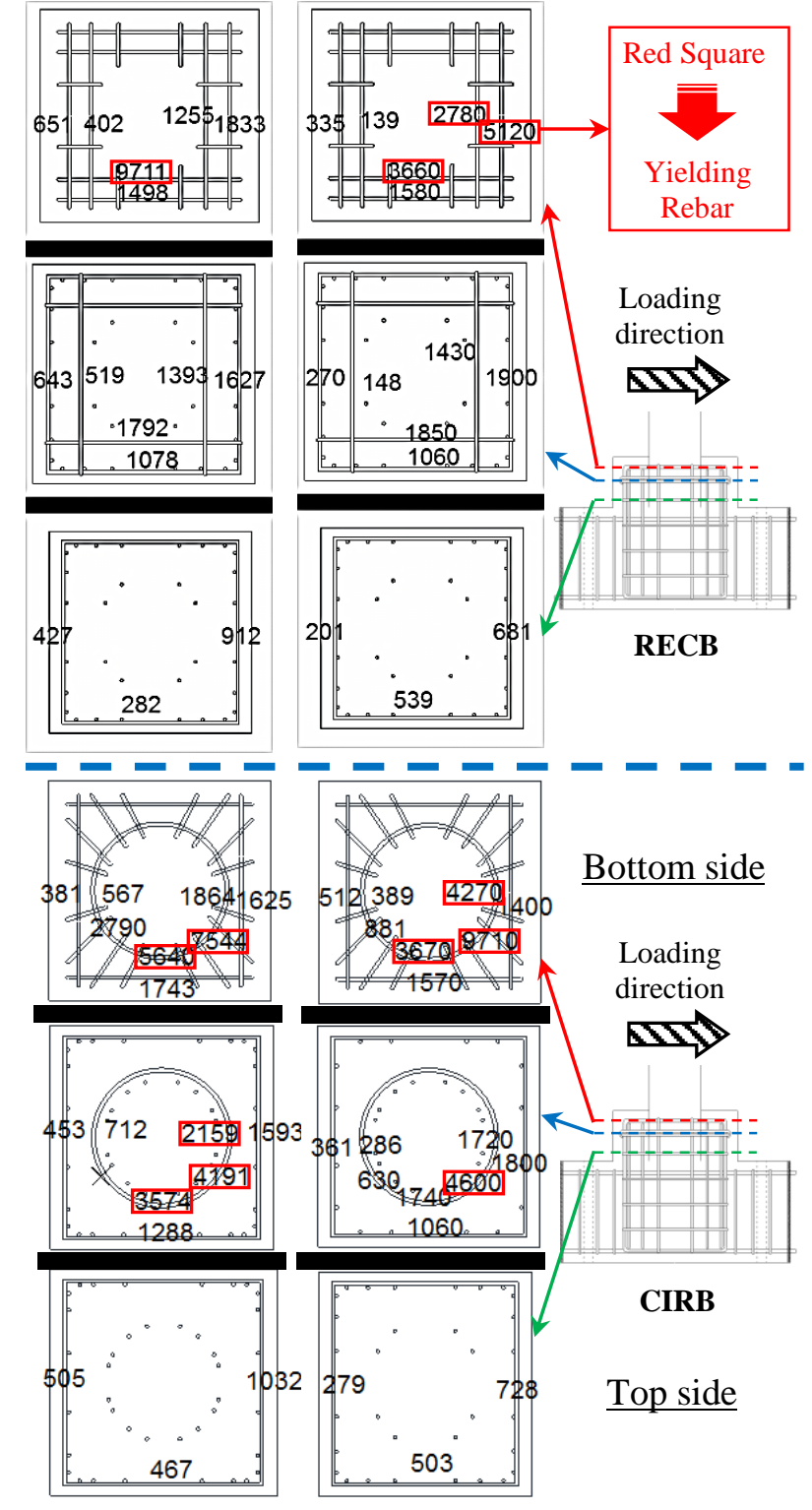

(a) Experience

(b) Analysis

Figure 5: Strain of transverse reinforcements at $R=2 \%$ (Left: experiment, Right: analysis)

consistent with the test results. A crack does not appear backwards loading direction in the analyses because the interface between the pile and pile cap can transmit only the compressive force and shear force caused by friction, but not the tensile force.

\subsection{Distribution of minor principal stress}

Figure 7 shows the distribution of minor principal stress of RECB when $R=2 \%$. The pile cap in loading direction was pushed out by the pile, and compressive stress was produced. Also, this figure indicates that the largest 
compression strut was formed in B-B' area which is similar to the crack patterns shown in Figure 6. This is because B-B' area has a larger stiffness than the stiffness for loading direction owing to the two directions of transverse bar arrangement. Figure 7 also shows that the compression strut developed from B-B' area to $\mathrm{C}-\mathrm{C}^{\prime}$ area which is constrained by the foundation beam. Furthermore, a high compressive stress was produced on the upper side of the footing backwards in loading (D-D' area). This stress was caused by a lever reaction force, like the pile pried the pile cap. Consequently, the transmission of the force from the pile to the pile cap consists of (1) compressive force acting on the bottom of the pile cap in loading direction side and (2) compressive force acting on the upper side of the pile cap in the opposite side to the loading direction and the friction force.

\section{ANALYSIS RESULTS OF SPECIMENS PRESTRESSED LATERALLY}

\subsection{Load $(Q)$-rotation angle $(R)$ relations}

Figure 8 shows load $(Q)$-rotation angle $(R)$ relations of RECB and the specimens prestressed laterally from two directions at the bottom side of the pile cap, P1-RECB (prestressing ratio $=0.025$ ), P3-RECB (prestressing ratio=0.075) and P6-RECB (prestressing ratio $=0.15$ ). With regard to the specimens prestressed laterally, the axial force was applied after the introduction of lateral prestress in consideration of an actual construction process. The mechanical properties of materials and the analytical models were basically similar to RECB, and a PS bar was modeled as elastic body. P1-RECB and $\mathrm{P} 3-\mathrm{RECB}$ having a lower prestressing ratio were significantly affected by the cracks in BB' area shown in Figure 7, and the vertical reinforcement in the loading direction shown in Figure 8 initially yielded. On the other hand, as for P6-RECB, the vertical reinforcement in the rear of loading direction shown in Figure 9 initially yielded. According to Figure 8, the stiffness became larger with increasing in the amount of prestressing force, however it

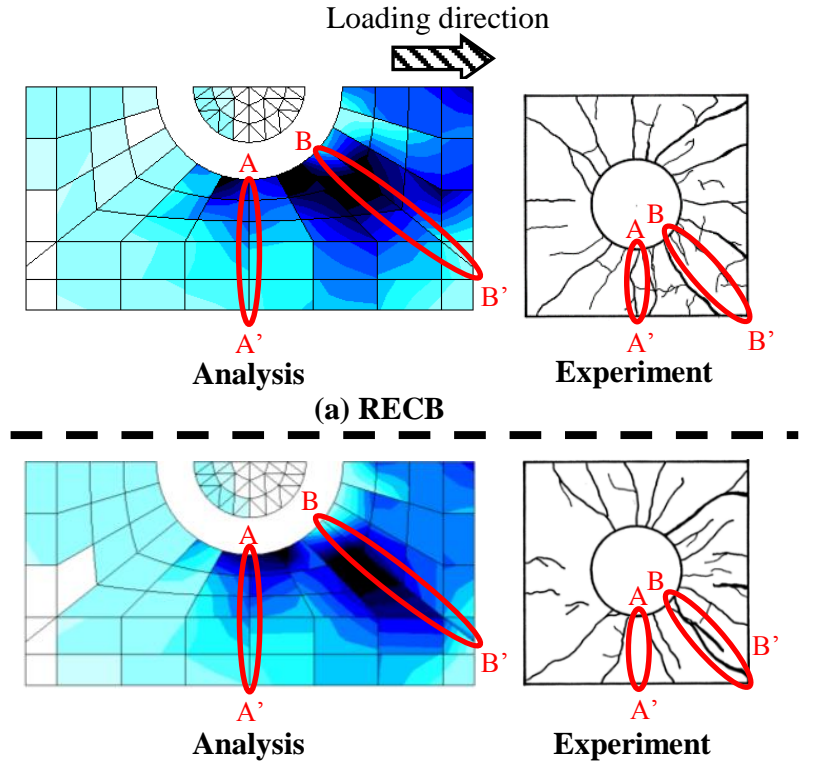

(b) CIRB

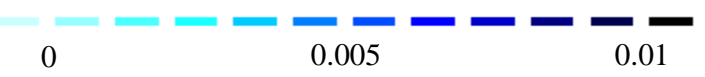

Figure 6: Crack patterns in analysis and experiments at $R=2 \%$

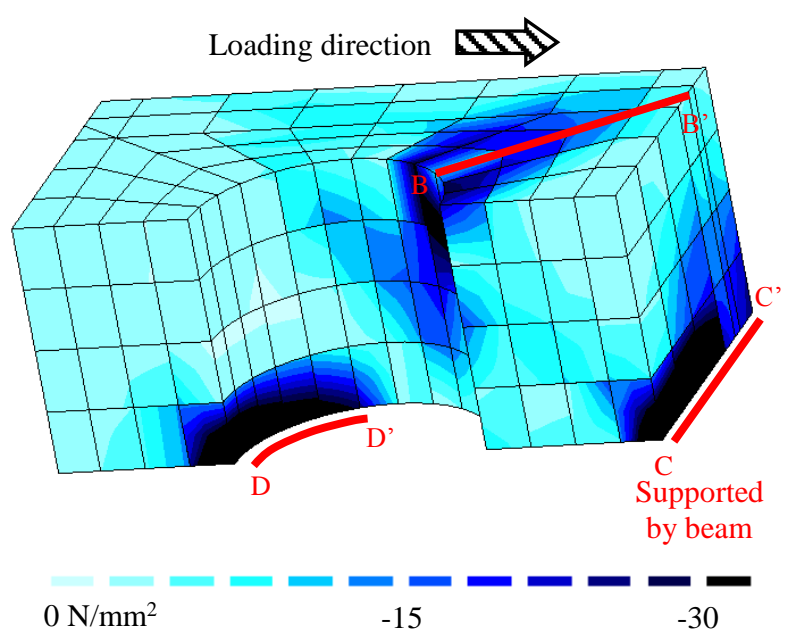

Figure 7: Distribution of minor principal stress of RECB at $R=2 \%$

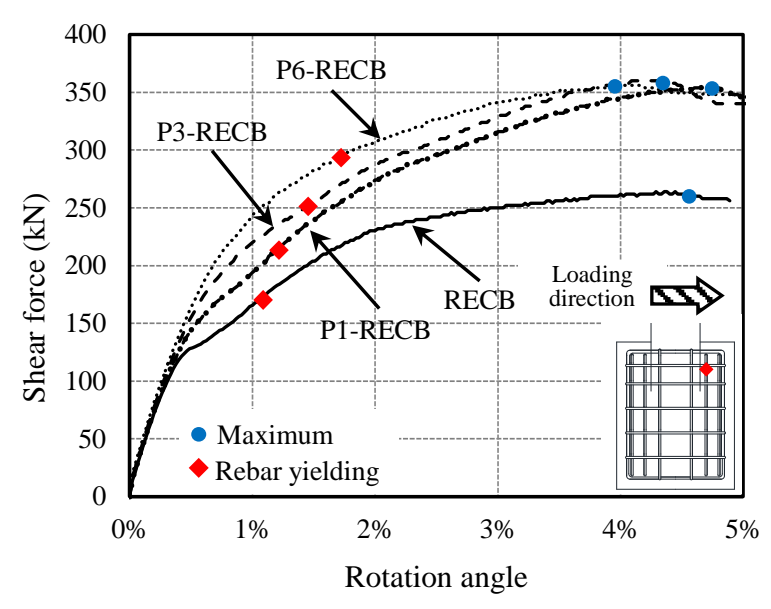

Figure 8: Load-rotation angle relations 
became closer value around $R=2 \%$, and the maximum capacity of prestressed specimens became finally almost similar. This was caused by the strain behavior of vertical reinforcement in the rear of loading direction shown in Figure 9. According to Figure 9, the vertical reinforcement in the rear of loading direction of RECB did not yield until $R$ reached 5\%, however those of prestressed specimens yielded around $R=2 \%$. For this reason, the deformation and the failure mode were governed by flexure, so that the maximum capacity of prestressed specimens had similar values regardless of the amount of prestressing forces.

\subsection{Crack patterns at $\mathrm{R}=\mathbf{2 \%}$}

Figure 10 compares cracking strain contour of P1-RECB with P6-RECB when $R=2 \%$. A crack in $\mathrm{B}-\mathrm{B}$ ' area became the widest crack for both specimens, however the crack opening was well controlled in comparison with RECB (shown in Figure 6). Especially, a crack in AA' area which was perpendicular to the direction of prestressing force was effectively controlled. A diagonal crack in B-B' area was also well controlled depending on the amount of prestressing force because the prestressing force was introduced from two directions. The shear crack strength was $130 \mathrm{kN}, 164 \mathrm{kN}, 202 \mathrm{kN}$ and $238 \mathrm{kN}$ in order of RECB, P1-RECB, P3RECB, and P6-RECB, where the shear crack strength of analysis was defined as the horizontal force that a crack strain exceeded $0.5 \%$. Thus, the shear crack strength became larger with an increase of the amount of prestressing force. Also, the widest crack strain became narrower with an increase of the amount of prestressing force.

\subsection{Degree of damage}

The degree of damage in the compressive zone of concrete was defined using the deviator stress component, $r$ on $\xi-r$ plane which is the invariant quantity of stress as shown in Figure 11. Namely, the degree of damage $D_{f}$ of stress point $P$ having the invariant quantity of stress $\left(\xi_{p}, r_{p}\right)$ was defined as $D_{f}=r_{p} / r_{f s}$, where $r_{f s}$ was the deviated stress component on the meridian of Drucker-Prager criterion for the hydraulic

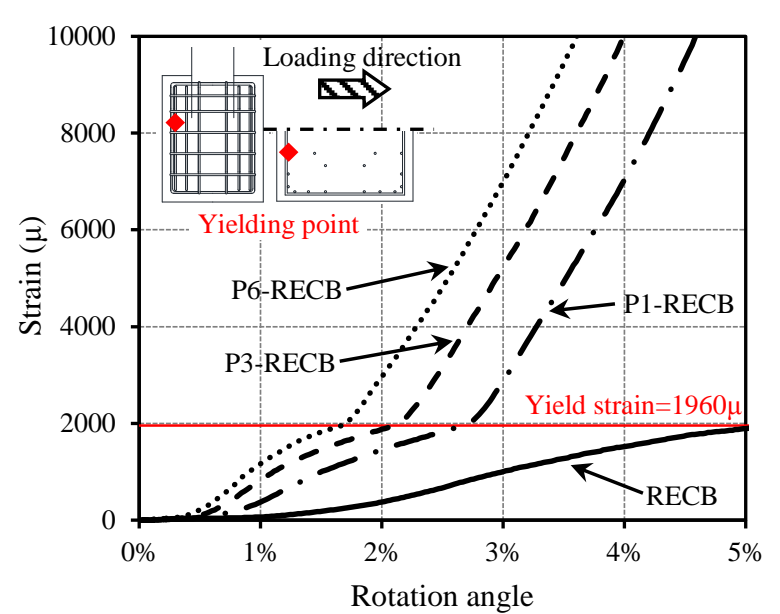

Figure 9: Strain of vertical reinforcement in the opposite side of loading direction

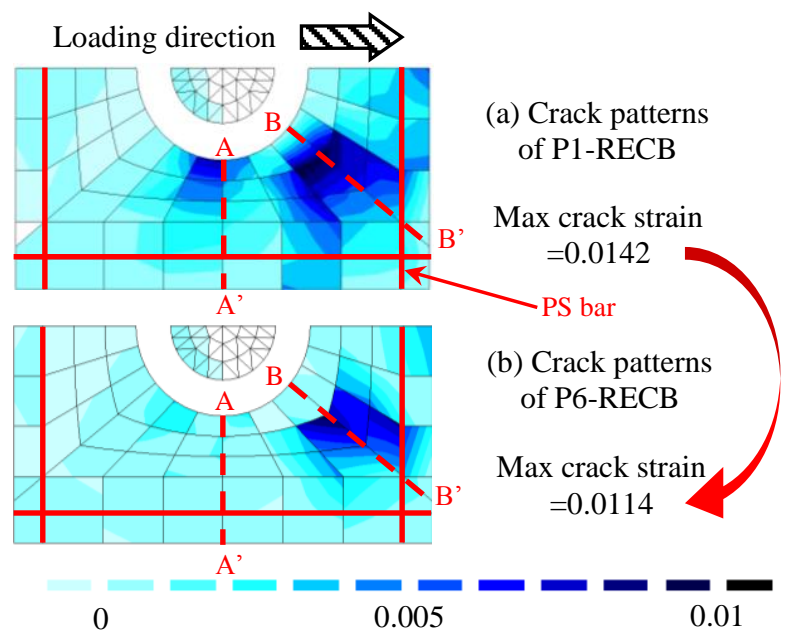

Figure 10: Comparison of crack patterns at $R=2 \%$

pressure component $\xi_{p}$. Thus, $D_{f}$ becomes 0 on the hydraulic pressure axis ( $\xi$ axis), there was no tensile and shear stress to any direction, on the other hand it becomes 1 on the failure surface. However, degree of damage turned to decreasing during the shrinking process of the failure surface due to the softening behavior after the maximum stress as shown in Figure 3. Figure 12 shows the degree of damage calculated at the integration point where was the closest plane to PS bar when $Q=150 \mathrm{kN}$. The damage around the steel pressure-resisting plates was heavy for P6-RECB because the vertical confinement of pile cap was relatively low. Meanwhile, the damage in B-B' area was effectively controlled.

\subsection{Equivalent confining pressure}

The concept of equivalent confining 


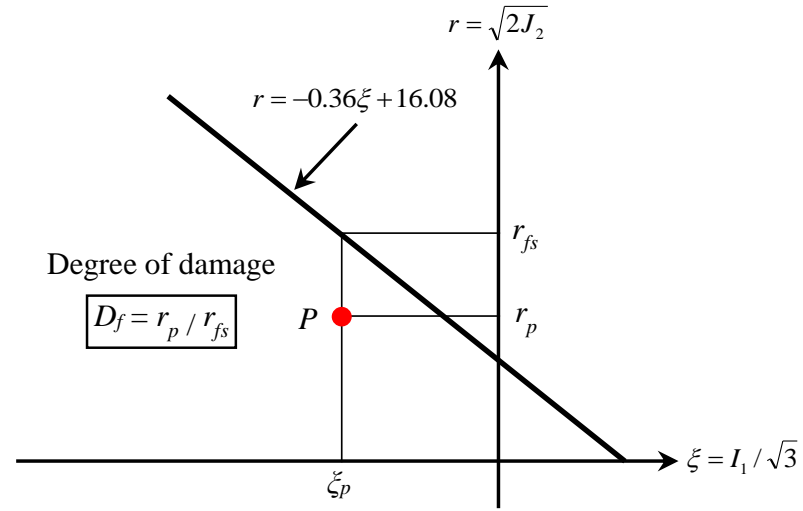

Figure 11: Definition of degree of damage

pressure by Mizuno et al. (1997) was applied to estimate the magnitude of the effectiveness of confinement on core concrete by lateral prestressing. The equivalent confining pressure is defined as the lateral pressure when the stress state on a random stress-path is converted into that on the stress-path according to the triaxial compressive test with a constant lateral pressure. Consequently, the equivalent confining pressure increased as the hydraulic component increased and as the deviated component of the stress state decreased in the principal stress space. Figure $\mathbf{1 3}$ shows the equivalent confining pressure at the integration point where was the closest plane to PS bar when $Q=150 \mathrm{kN}$. A-A' and B-B' area of P6-RECB was effectively confined due to prestress, and also a crack was controlled. High confining pressure was observed near the pile for P1RECB because the compressive stress caused by friction force when the pile pressed against the pile cap with increasing in horizontal displacement.

\subsection{Stress of prestressing bar}

The stress of PS bar became larger compared to the initial prestress as a crack width increased because PS bar constrained the cracks from opening. Figure 14 shows the stress of PS barrotation angle $(R)$ relations. The stress increase of PS bar was the largest in the loading direction, and it contributed to controlling cracks. Especially, the stress level of P1-RECB having a small prestress increased greatly and reached almost the same stress levels of the other two specimens. Since the stress increase

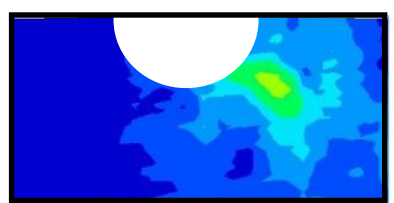

(a) P1-RECB

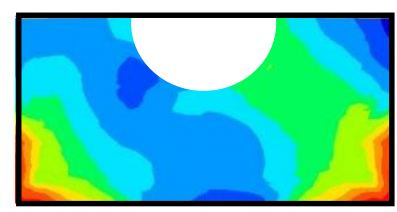

(b) P3-RECB

Figure 12: Degree of damage at $Q=150 \mathrm{kN}$

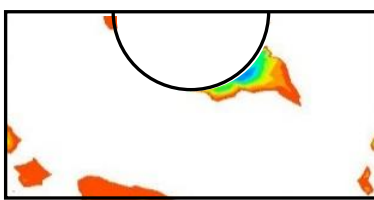

(a) P1-RECB

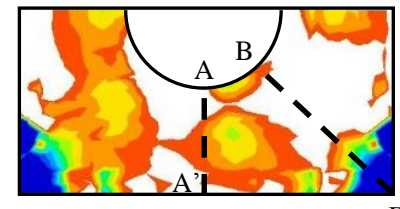

(c) P6-RECB

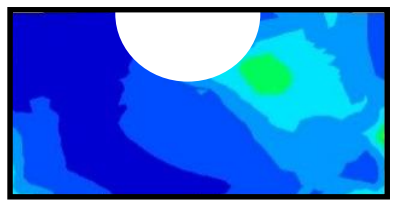

(c) P6-RECB
0.5
0

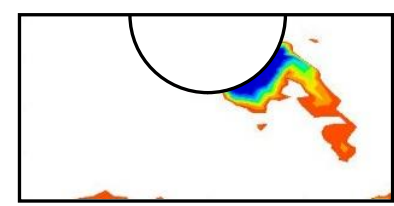

(b) P3-RECB

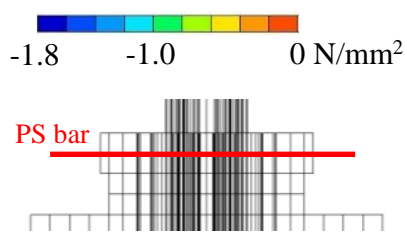

Figure 13: Equivalent confining pressure at $Q=150 \mathrm{kN}$

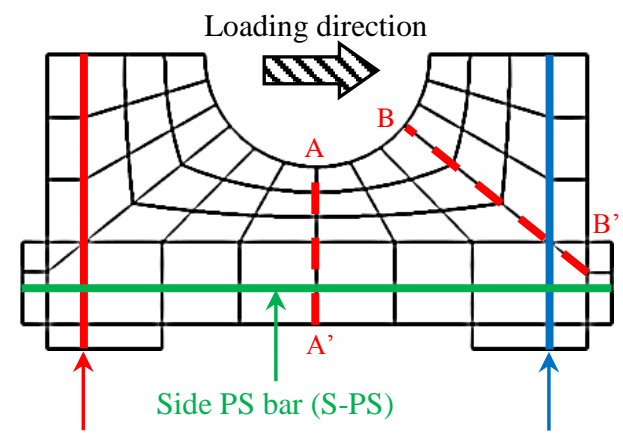

Back PS bar (B-PS)

Front PS bar (F-PS)

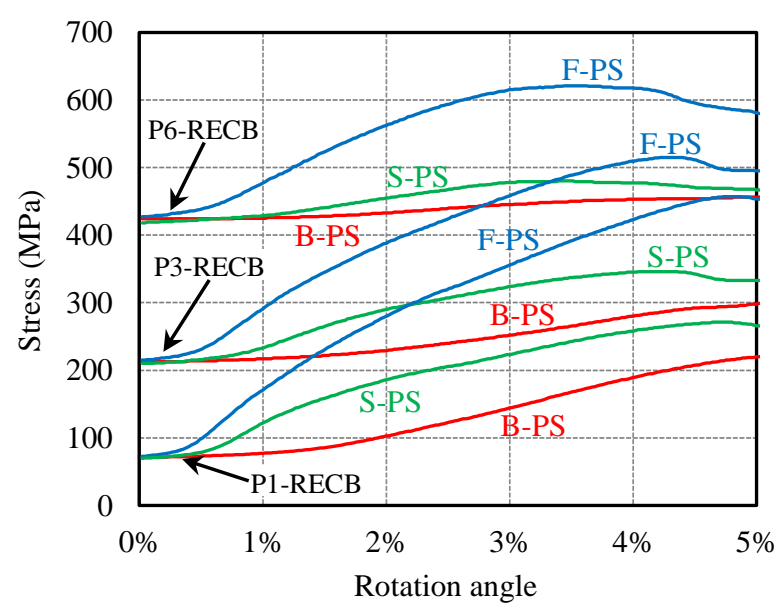

Figure 14: Stress of PS bars-rotation angle relations 
of PS bar is equivalent to the strain increment which means an increase of a crack width, P3RECB having a high prestress can very well control a width of crack. In this analysis, PS bar was assumed to be elastic and a diameter was relatively thick. Generally, a diameter of PS bar should be decided by an allowable crack width because the stiffness against crack opening becomes higher as a diameter of PS bar increases.

\subsection{Analysis results of L-RECB and L-P6- RECB}

Figure 15 shows the finite element model of a redoubled specimen, L-P6-RECB. Figure 16 shows load $(Q)$-rotation angle $(R)$ relations of RECB, L-RECB (having a double dimension of RECB), P6-RECB and L-P6-RECB. The maximum capacity of L-RECB was determined by the opening of the crack to B-B' direction, and that of L-P6-RECB by a flexural failure mode which are similar to the half size specimens. Comparing the increase ratio of the maximum capacity due to the introduction of prestressing force when $R=1 \%$, it was $47 \%$ for P6-RECB and $28 \%$ for L-P6-RECB. When $R=2 \%$, it was $33 \%$ for $\mathrm{P} 6-\mathrm{RECB}$ and $25 \%$ for L-P6-RECB. Thus, increase ratio of the maximum capacity became lower in case of the large specimen. This may be caused by weakening the effect of confinement with increasing in the dimension of the specimens.

Figure 17 shows the degree of damage calculated from the integration point at the level of PS bar when $R=1 \%$. The degree of damage of B-B' direction of L-P6-RECB became greater, and this damage restrained the increase ratio of the maximum capacity. Figure 18 shows the degree of damage when $R=2 \%$. The degree of damage near the pile of B-B' area became smaller compared to when $R=1 \%$. This phenomenon indicates that the stress of concrete exceeded the maximum stress and entered the softening zone. Since $r_{f s}$ in Figure $\mathbf{1 1}$ is defined by an initial failure surface, the degree of damage is evaluated to be small even if a stress point is on the failure surface.

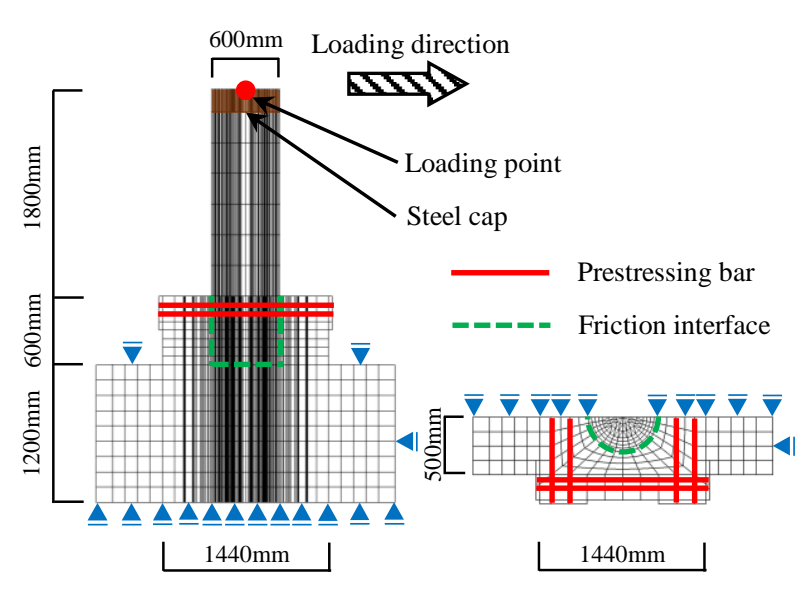

(a) Elevation

(b) Section

Figure 15: Finite element mesh (L-P6-RECB)

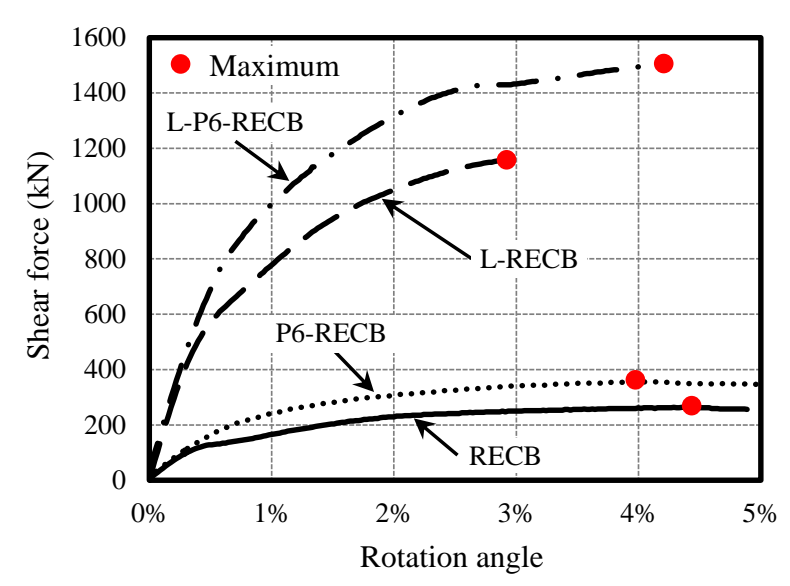

Figure 16: Load-rotation angle relations

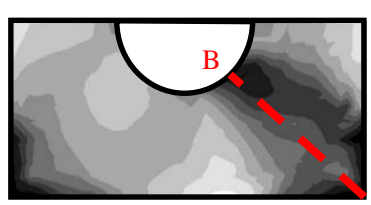

(a) P6-RECB

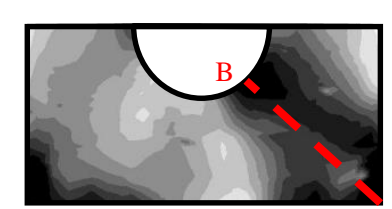

(b) L-P6-RECB B'
Figure 17: Degree of damage at $R=1 \%$

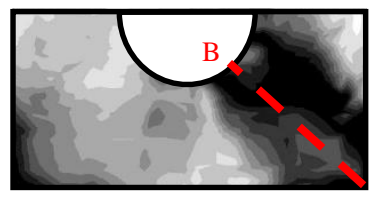

(a) P6-RECB

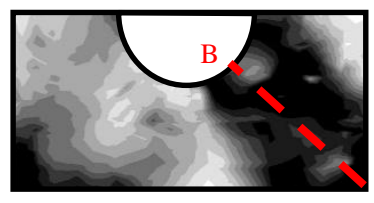

(b) L-P6-RECB

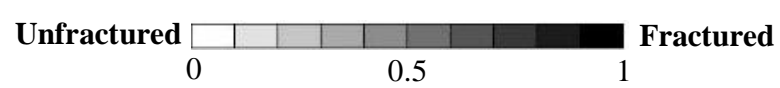

Figure 18: Degree of damage at $R=2 \%$ 


\section{CONCLUSIONS}

3D FEM analyses were performed on the pile caps prestressed laterally and following conclusions were obtained.

1) Test results can be reproduced by inserting the interface between the pile and pile cap.

2) The lateral prestress introduced at the bottom side of the pile cap controls the shear crack effectively and increases the shear capacity of the pile cap by over 30 percent.

3) The width of crack can be well controlled by increasing the prestressing force.

4) The degree of damage of core concrete due to the lateral prestress was evaluated based on the triaxial state of stress in each integration point level.

5) The effect of the confinement by reinforcing and prestressing bars is diminishing with increasing in the dimension of the specimens.

6) In this analysis, only lateral prestress was introduced to the pile cap without vertical prestress. Therefore the introduction of vertical prestress in addition to lateral prestress to the pile cap may prevent yielding of vertical reinforcements and further improve the shear capacity.

\section{REFERENCES}

[1] Kokusho, S. et al. 1983. Studies on the Behavior of Pile-Footing Connections under Axial and Lateral Forces (Part 1, 4). Summary of Technical Papers of Annual Meeting of Architectural Institute of Japan (In Japanese)

[2] Shinohara, Y. et al. 2004. Active Confining Effect and Failure Mechanism for R/C Columns Prestressed Laterally. Journal of Structural and Construction Engineering, AIJ, No. 558: pp. 115-121. (In Japanese)

[3] Popovics, S. 1973. A Numerical Approach to the Complete Stress - Strain Curve of Concrete. Cement and Concrete Research, Vol. 3: pp. 583-599

[4] Architectural Institute of Japan. 1999. Design Standard for Steel Structures. (In Japanese)

[5] Hayashi, S. et al. 1982. Experimental Study of the Bond Behaviour of Reinforcing Bars Subjected to the Simultaneous Push and Pull. Journal of Structural and Construction Engineering, AIJ, No. 322: pp. 52-63. (In Japanese)

[6] Mizuno, E., and Hatanaka, S. 1997. Development of a Strain-Softening Type Concrete Constitutive Model and 3-D FEM Analyses for Confined Concrete. Proceedings of the Japan Society of Civil Engineers, No. 571, V-36: pp. 185-197. (In Japanese)

[7] TNO DIANA. Diana User's Manual Release 9.4.4. 